\title{
Surgical Management and Outcomes of Aneurysms of Posterior Inferior Cerebellar Artery: Location-Based Approaches with Review of Literature
}

\author{
Harsh Deora ${ }^{1}$ Nitish Nayak ${ }^{2}$ Priyadarshi Dixit ${ }^{2} \quad$ V. Vikas² $\quad$ K. V. L. Narasinga Rao ${ }^{2}$ Nupur Pruthi² \\ Dwarakanath Srinivas $^{2}$ Dhaval P. Shukla² Dhananjay I. Bhat ${ }^{2}$ Bhaskara Rao Malla ${ }^{2}$ Bhagvatula Indira Devi ${ }^{2}$ \\ Sampath Somanna \\ ${ }^{1}$ Department of Neurosurgery, Sanjay Gandhi Postgraduate \\ Institute of Medical Sciences, Lucknow, Uttar Pradesh, India \\ ${ }^{2}$ Department of Neurosurgery, National Institute of Mental Health \\ and Neurosciences, Bengaluru, Karnataka, India \\ Address for correspondence K. V. L. Narasinga Rao, MCh, \\ Department of Neurosurgery, National Institute of Mental \\ Health and Neurosciences, Bengaluru - 560 029, Karnataka, India \\ (e-mail: neuronarsi@gmail.com).
}

J Neurosci Rural Pract 2020;11:34-43

\begin{abstract}
Keywords

- far-lateral approach

- posterior inferior cerebellar artery aneurysm

- subarachnoid hemorrhage

- suboccipital approach Background Posterior inferior cerebellar artery (PICA) is a tortuous, variable, and uncommon site for aneurysms. Surgical management of PICA aneurysms involves careful selection of approach based on the location of the aneurysm and meticulous dissection of the neurovascular structures and perforators.

Materials and Methods We did a retrospective review of all the PICA aneurysms operated at our institute in the past 10 years along with the site, presentation, and approach used for the same. Preoperative World Federation of Neurosurgical Society scores and follow-up modified Rankin scores (mRS) were also evaluated. During the same period, data for intervention cases of PICA aneurysm were also collected with follow-ups for a comparative analysis.

Results A total of 20 patients with 21 PICA aneurysms were reviewed. All the reviewed cases presented with subarachnoid hemorrhage, and the most common location was the lateral medullary segment and vertebral artery (VA)-PICA junction. Midline approaches were used for distal PICA cases, with far-lateral approach reserved for anterior medullary/VA-PICA junction. No lower cranial nerve palsies were recorded at follow-up. Four cases needed cerebrospinal fluid diversion and two developed cerebellar infarcts. All cases were mRS 0 to 2 at follow-up.

Conclusion Our series compares well with some of the larger surgical series of PICA aneurysms. This may be due to early referral patterns and early surgery ( $<24$ hours) policy at our institution. Anatomical knowledge of PICA anatomy and sound perioperative management are keys to good outcomes in these cases.
\end{abstract}

\section{Introduction}

Posterior circulation aneurysms arise from vertebral arteries (VAs), basilar arteries (BAs), or their branches. Aneurysms of the posterior inferior cerebellar artery (PICA) comprise 0.5 to $3 \%$ of all intracranial aneurysms. They, however, pose a significant risk because of their high morbidity, mortality, and rupture rate. Furthermore, re-bleeding rates are high (78\%)

DOI https://doi.org/ 10.1055/s-0039-3399486 ISSN 0976-3147. primarily due to their relatively thin aneurysm wall and dissecting nature. ${ }^{1}$ Microsurgical approach is limited by anatomical corridors of brain stem, petrous occipital bone, and multiple neurovascular structures occupying the cerebellomedullary and cerebellopontine cisterns. ${ }^{2}$ Adding to our misery is the fact that PICA is the most variable artery in terms of its course among all arteries of the posterior circulation. ${ }^{3}$ The first ligation of cervical VA due to an intracranial aneurysm 
was reported by Dandy in $1928 .{ }^{4}$ In 1947, Rizzoli and Hayes trapped and excised a PICA aneurysm. ${ }^{5}$ In recent years, the trend of treatment of posterior circulation aneurysms has tilted toward the endovascular arm.

PICA usually originates from the V4 segment, while extracranial origin from V3 has been described. Aneurysms from PICA can originate from one of its six segments and two loops (based on its relationship with the medulla oblongata and the cerebellum) that include (a) the VA-PICA junction, (b) the anterior medullary segment extending from VA-PICA's origin to the inferior olivary prominence, (c) the lateral medullary segment extending till the origin of IX-X-XI cranial nerves (CNs) from the brain stem, (d) the tonsillomedullary segment extending till the caudal portion of tonsil (including the caudal loop), (e) the telovelotonsillar segment which extends from the midportion of its ascent along the medial surface of tonsil to the cortical cerebellar surface (including the cranial loop), and (f) the cortical segment, extending till the cerebellar vermis and hemisphere $(- \text { Fig. 1) })^{3,6}$

Here, we retrospectively analyzed 20 such cases of PICA aneurysm operated at our institute, with special emphasis on the presentation and nuances of approach based on the segment of the aneurysm and outcomes.

\section{Materials and Methods}

All operated cases of PICA aneurysm from February 2012 to May 2017 were retrospectively reviewed. All aneurysms were identified using digital subtraction angiography (DSA).

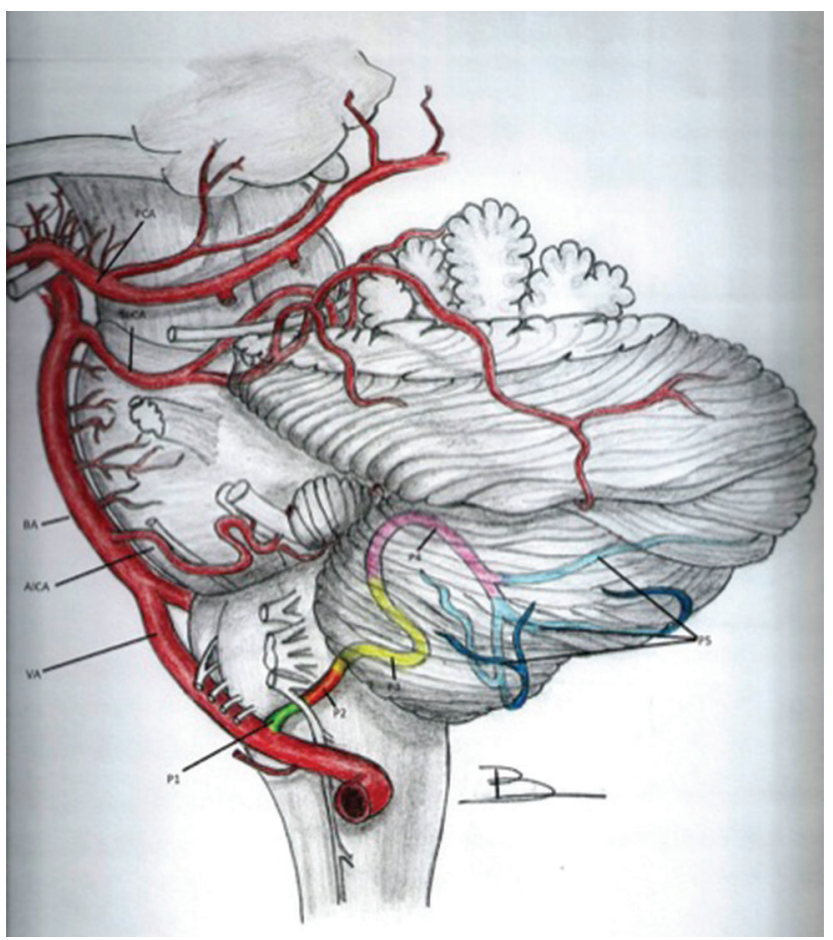

Fig. 1 Schematic representation of the normal anatomy of (left) posterior inferior cerebellar artery. AICA, anterior inferior cerebellar artery; BA, basilar artery; P1, anterior medullary segment; P2, lateral medullary segment; P3, tonsillo-medullary segment; P4: telovelotonsillar segment; P5, cortical segment; PCA, Posterior cerebellar artery; SuCA, superior cerebellar artery; VA, vertebral artery.
Data were collected from patient records under the following heads: demography, presentation, World Federation of Neurosurgical Society (WFNS) grade, and computed tomography (CT) findings. Aneurysm location and anatomy with respect to the management strategy and postoperative neurological complications were analyzed in light of their location on DSA. In cases of multiple aneurysms, the site of rupture was decided based on CT findings, size and irregularity of the aneurysm, or findings in surgery or at an autopsy or both. Patient outcomes were analyzed using modified Rankin scores (mRS) at the time of discharge and at follow-up.

Simultaneously, data for PICA aneurysms undergoing intervention were also sought. This included presentation, segment of aneurysm, associated vascular abnormalities and course, and clinical follow-up data. However, as the series has limited numbers on both sides, a direct comparison in the outcomes was not sought.

Because the data have been sourced from a tertiary care hospital in India, cost was one of the major deciding factors in the treatment decision. Only cases deemed unsuitable by the operating surgeon and those with the available resources for intervention were referred for the same, hence the predominance of surgical intervention in this series.

\section{Operative Approach}

We usually approach PICA aneurysms using the midline suboccipital route. Proximal control of the VA was attained early by dissecting the vertebral artery intradurally, just after its dural entry. Foramen magnum rim was removed in all cases, but we did not drill the occipital condyle, as it was not considered essential for adequate exposure. The origin of PICA is usually found near the root exit zone of the hypoglossal nerve. Proximal perforators, particularly to the brain stem, often pose a challenge in adequately delineating the aneurysm. The aneurysmal neck was defined by sharp dissection while being mindful on the critical neurovascular structures surrounding it. The course and tortous nature of the VA-BA complex needs to be considered when deciding the approach to the aneurysm, that is, use either the midline sub occipital craniotomy or the far lateral approach. Intraoperatively, no aneurysmal rupture was recorded. We used the far-lateral approach along with lateral occipital condyle resection in VA-PICA aneurysms (-Table 1).

\section{Results}

\section{Demographics and Clinical Presentation}

A total of 20 cases with 21 PICA aneurysms were analyzed. In one case with multiple aneurysms, one PICA junctional aneurysm was present along with left superior hypophyseal artery and left communicating segment ICA aneurysm. Another case had two PICA aneurysms: one in the tonsillomedullary segment and another in the cortical segment. Among all the 20 patients, 12 were female and 8 were male (male: female $=2: 3$ ). All patients presented with aneurysmal rupture and subarachnoid hemorrhage (SAH) ( - Fig. 2) with or without intraventricular hemorrhage (IVH). The mean 
Table 1 Approach and location of aneurysms based on digital subtraction angiography

\begin{tabular}{|c|c|c|}
\hline Location of aneurysm & $\begin{array}{l}\text { Surgical } \\
\text { approach }\end{array}$ & $\begin{array}{l}\text { Number of } \\
\text { aneurysms } \\
(n=21)\end{array}$ \\
\hline \multirow[t]{2}{*}{$\begin{array}{l}\text { VA/BA-PICA junction/ } \\
\text { anterior medullary }\end{array}$} & $\begin{array}{l}\text { Far-lateral } \\
\text { approach }\end{array}$ & 4 \\
\hline & $\begin{array}{l}\text { Midline } \\
\text { suboccipital } \\
\text { craniectomy }\end{array}$ & 3 \\
\hline \multirow[t]{2}{*}{ Lateral medullary } & $\begin{array}{l}\text { Far-lateral } \\
\text { approach }\end{array}$ & 1 \\
\hline & $\begin{array}{l}\text { Midline } \\
\text { suboccipital } \\
\text { craniectomy }\end{array}$ & 3 \\
\hline \multirow[t]{2}{*}{$\begin{array}{l}\text { Tonsillomedullary/pos- } \\
\text { terior medullary }\end{array}$} & $\begin{array}{l}\text { Far-lateral } \\
\text { approach }\end{array}$ & 1 \\
\hline & $\begin{array}{l}\text { Midline } \\
\text { suboccipital } \\
\text { craniectomy }\end{array}$ & 7 \\
\hline \multirow[t]{2}{*}{ Telovelotonsillar } & $\begin{array}{l}\text { Far-lateral } \\
\text { approach }\end{array}$ & None \\
\hline & $\begin{array}{l}\text { Midline } \\
\text { suboccipital } \\
\text { craniectomy }\end{array}$ & 1 \\
\hline \multirow[t]{2}{*}{ Cortical } & $\begin{array}{l}\text { Far-lateral } \\
\text { approach }\end{array}$ & None \\
\hline & $\begin{array}{l}\text { Midline } \\
\text { suboccipital } \\
\text { craniectomy }\end{array}$ & 1 \\
\hline
\end{tabular}

Abbreviations: BA, basilar artery; PICA, posterior inferior cerebellar artery; VA, vertebral artery.

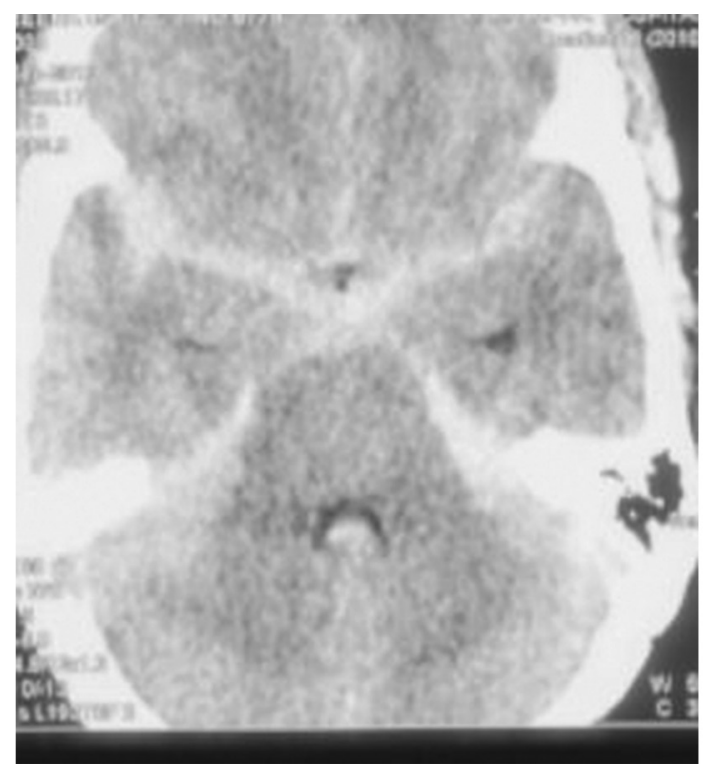

Fig. 2 Preoperative plain computed tomography scan showing presentation of a case with extensive subarachnoid hemorrhage. interval between ictus and surgery was 29 days (range: 1-300 days). As expected, sudden-onset severe "thunderclap" holocranial headache was the presenting feature in 18 patients; 7 patients had transient loss of consciousness and 2 had associated seizures (generalized tonic-clonic seizures). Difficulty in swallowing and hoarseness of voice was present in one patient. Sixteen patients had WFNS Grade 1, two patients had Grade 2, and two patients had Grade 4 (-Table 2).

\section{Radiological Analysis}

All the patients who presented with acute symptoms suggestive of aneurysmal rupture underwent CT within 24 to 48 hours after the ictus ( - Table 3 ). Hydrocephalus was present in six (30\%) patients ( $\boldsymbol{- \text { Fig. }}$ 3). Of all the cases only one required preoperative external ventricular drain and another patient needed cerebrospinal fluid (CSF) drainage intraoperatively which was carried over postoperatively as well ( - Fig. 4A). We had one case of junction aneurysm with retrograde filling in left VA. In one case with multiple aneurysms, one PICA junction aneurysm was present along with left superior hypophyseal artery and left communicating segment ICA aneurysm ( - Fig. 4B). One case of double aneurysm was also present with a tonsillomedullary segment aneurysm and another in the cortical segment ( - Fig. 5). Only one aneurysm was giant (>25 mm) in size.

\section{Presurgical Management}

In patients admitted within 3 weeks of ictus, oral nimodipine along with mannitol was started. Following angiography to confirm the location and morphology of the aneurysm, surgery was performed as early as possible. The surgical approaches included midline suboccipital craniotomy $(n=15)$ for aneurysms located near the midline and far lateral approach $(n=5)$ for aneurysms located anterior to the brainstem and at the BA VA PICA junction.

\section{Complications and Outcome}

All the 20 patients were available for follow-up. Nearly $75 \%(15 / 20)$ of the patients were functionally independent $(\mathrm{mRS}=0-2)$ at the time of discharge. Among the remaining five cases, three cases improved to mRS of 0 to 2 . The mean duration of hospital stay was 8.15 days (range: 5-21 days). Eighteen patients were discharged home and two required rehabilitation. Around 20\% (4) of the patients had new postoperative neurological deficits comprising neurological complications. Nearly $10 \%$ (2) of the patients developed left-sided weakness that improved with physiotherapy to $>3 / 5$. The other $10 \%$ (2) of patients developed new postoperative cerebellar signs. One patient who had presented with lower CN symptoms continued to remain the same postoperatively with mild improvement subjectively at 6-month follow-up visit. Both cases were operated via a midline suboccipital craniotomy approach, and one developed left cerebellar infract detected on CT. Four cases (20\%) required ventriculo peritoneal 
Table 2 Demography, presentation, morphology, and outcomes of posterior inferior cerebellar artery aneurysms

\begin{tabular}{|c|c|c|c|c|c|}
\hline Age and sex & Symptoms at presentation & $\begin{array}{l}\text { WFNS } \\
\text { grade }\end{array}$ & $\begin{array}{l}\text { Interval from } \\
\text { ictus (days) }\end{array}$ & $\begin{array}{l}\text { Aneurysmal } \\
\text { morphology }\end{array}$ & Postoperative status \\
\hline 53 and female & Headache and vomiting & 1 & 4 & Bilobed aneurysm & No new deficits \\
\hline 38 and female & $\begin{array}{l}\text { Headache, transient loss of } \\
\text { consciousness, and difficul- } \\
\text { ty in swallowing }\end{array}$ & 1 & 23 & $\begin{array}{l}\text { Multilobed } \\
\text { aneurysm }\end{array}$ & $\begin{array}{l}\text { Right lower cranial nerve } \\
\text { palsy persistent }\end{array}$ \\
\hline 53 and female & Headache and vomiting & 2 & 4 & Saccular aneurysm & No new deficits \\
\hline 70 and male & Headache and vomiting & 1 & 4 & Saccular aneurysm & No new deficits \\
\hline 65 and female & $\begin{array}{l}\text { Headache, vomiting, } \\
\text { and transient loss of } \\
\text { consciousness }\end{array}$ & 4 & 2 & Saccular aneurysm & No new deficits \\
\hline 54 and female & Headache and vomiting & 2 & 2 & Saccular aneurysm & No new deficits \\
\hline 45 and male & Headache & 1 & 6 & Saccular aneurysm & Left hemiparesis \\
\hline 70 and male & $\begin{array}{l}\text { Headache, vomiting, and } \\
\text { neck stiffness }\end{array}$ & 1 & 2 & Saccular aneurysm & $\begin{array}{l}\text { Bilateral cerebellar } \\
\text { symptoms }\end{array}$ \\
\hline 53 and male & $\begin{array}{l}\text { Headache, vomiting, and } \\
\text { seizure }\end{array}$ & 1 & 15 & Fusiform & No new deficits \\
\hline 53 and female & $\begin{array}{l}\text { Headache and transient loss } \\
\text { of consciousness }\end{array}$ & 4 & 3 & Fusiform & No new deficits \\
\hline 52 and male & Headache & 1 & 10 months & Saccular aneurysm & No new deficits \\
\hline 45 and female & Headache and vomiting & 1 & 1 & Multiple lobes & No new deficits \\
\hline 35 and female & Headache & 1 & 6 months & Multiple lobes & No new deficits \\
\hline 35 and male & $\begin{array}{l}\text { Transient loss of } \\
\text { consciousness }\end{array}$ & 1 & 1 & Saccular aneurysm & No new deficits \\
\hline 52 and male & $\begin{array}{l}\text { Headache and transient loss } \\
\text { of consciousness }\end{array}$ & 1 & 15 & Saccular aneurysm & No new deficits \\
\hline 46 and female & $\begin{array}{l}\text { Headache, vomiting, and } \\
\text { neck stiffness }\end{array}$ & 1 & 7 & Saccular aneurysm & No new deficits \\
\hline 58 and female & $\begin{array}{l}\text { Headache, vomiting, } \\
\text { and transient loss of } \\
\text { consciousness }\end{array}$ & 1 & 5 & Saccular aneurysm & No new deficits \\
\hline 65 and female & Headache and vomiting & 1 & 2 & Saccular aneurysm & No new deficits \\
\hline 55 and male & Giddiness & 1 & 2 & Saccular aneurysm & No new deficits \\
\hline 77 and female & Headache and vomiting & 1 & 2 & Saccular aneurysm & No new deficits \\
\hline
\end{tabular}

Abbreviation: WFNS, World Federation of Neurosurgical Society.

Table 3 Preoperative plain computed tomography findings

\begin{tabular}{|l|l|}
\hline Feature on plain CT & $\begin{array}{l}\text { Number of patients } \\
(n=20), n(\%)\end{array}$ \\
\hline SAH & $8(40)$ \\
\hline $\begin{array}{l}\text { Bleed in supra- and infraten- } \\
\text { torial cistern }\end{array}$ & $4(20)$ \\
\hline IVH & $16(80)$ \\
\hline $\begin{array}{l}\text { Exclusively fourth ventricular } \\
\text { blood }\end{array}$ & $5(25)$ \\
\hline $\begin{array}{l}\text { Lateral, third and fourth ven- } \\
\text { tricular bleed }\end{array}$ & $11(55)$ \\
\hline HCP & $6(30)$ \\
\hline Cerebellar bleed & $3(15)$ \\
\hline
\end{tabular}

Abbreviations: $\mathrm{CT}$, computed tomography; HCP, hydrocephalus; IVH, intraventricular hemorrhage; SAH, subarachnoid hemorrhage. shunting which includes 2 cases with EVD placement (see above) and 2 others who presented after 1 month with headache and vomiting with $\mathrm{CT}$ showing ventricular dilatation. DSA/CT angiography was performed in all cases either immediately on postoperative day 1 or on follow-up at 6 weeks, depending on the surgeons preference $(-$ Fig. $\mathbf{6 A})$. None of the angiograms revealed any evidence of residual aneurysm.

\section{Comparison to Intervention}

During the same period, a total of five PICA aneurysms underwent coiling. All cases presented with SAH and were investigated with angiography. As the experience, of managing PICA aneurysms at our institute has grown the treatment of more proximally placed PICA aneurysms has shifted toward coiling, a trend which can be made out with the cases treated by endovascular methods ( - Table 4 ). 


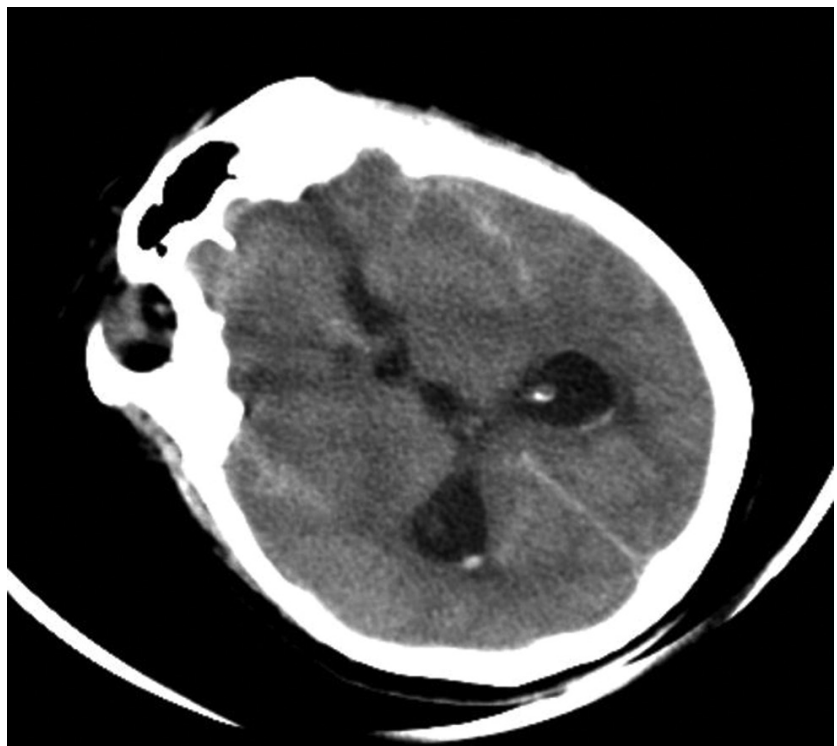

Fig. 3 Preoperative plain computed tomography scan showing presentation of case with subarachnoid hemorrhage and preoperative hydrocephalus mandating extraventricular drain placement.

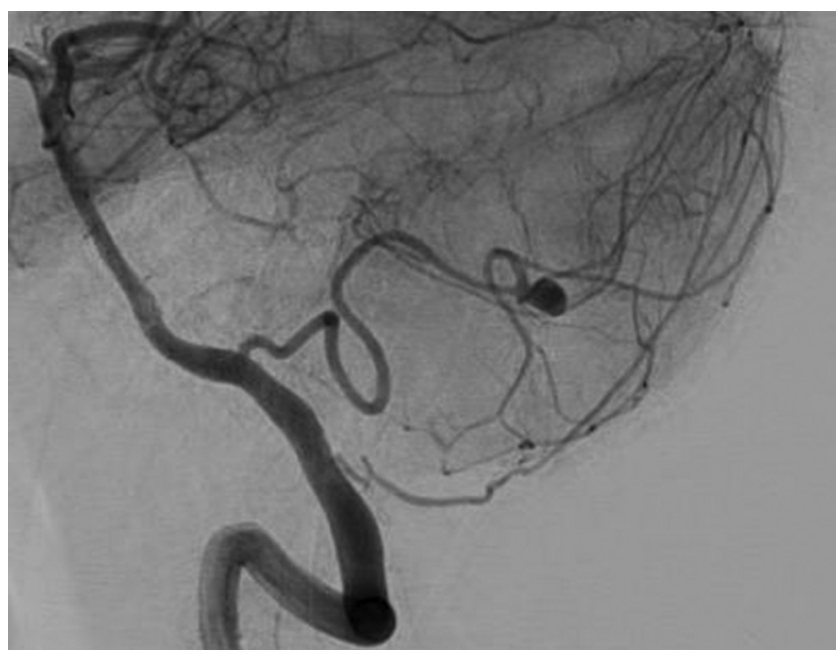

Fig. 4 Preoperative digital subtraction angiography showing saccular aneurysm in the 4 th segment of posterior inferior cerebellar artery.

This excludes a single case of cortical segment aneurysm with vermian arteriovenous malformation (AVM) ( - Figs. 6B and 7), where despite being explained the benefit of surgery, the patient opted for intervention. He deteriorated post procedure to E1M3VT status, and subsequent magnetic resonance imaging showed development of early brain stem infarcts and subsequently hydrocephalus. Following shunt surgery, the patient was discharged and did not report to follow-up.

\section{Discussion}

The largest review of PICA aneurysms has been conducted by Peerless and Drake ${ }^{7}$ who reviewed 146 cases of PICA aneurysms and classified outcomes as excellent, good, poor, and dead, without any objectivity in their outcomes. Overall, however, PICA aneurysms are rare $(0.49-3.0 \%)$ of all intracranial aneurysms. However, these aneurysms present with

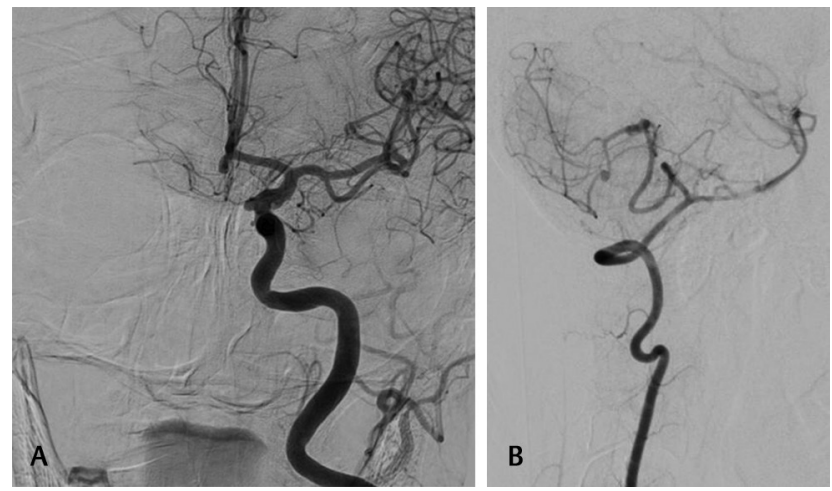

Fig. 5 (A) Preoperative digital subtraction angiography of multiple aneurysm case showing medially directed supraclinoid inferior cerebellar artery aneurysm and another anterior communicating segment aneurysm. (B) Preoperative digital subtraction angiography of multiple aneurysm case showing a double posterior inferior cerebellar artery aneurysm, with one in the tonsillo-medullary segment and the other in the cortical segment.

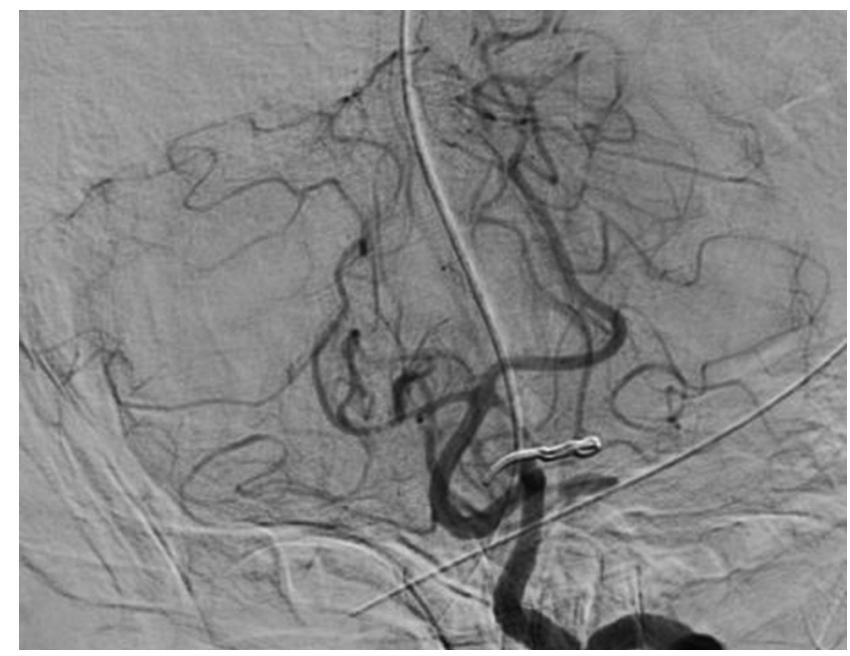

Fig. 6 Postoperative digital subtraction angiography showing clip in situ with complete obliteration of aneurysm sac.

poor initial neurological status. This is because of the location of this aneurysm. Over $83 \%$ of these cases present with IVH as the blood enters from the foramen of Luschka or Magendie and tracks intraventricularly. ${ }^{8}$ Furthermore, these aneurysms have a high re-bleeding rate (78\%) and dissecting nature. In our series too, IVH rates were $80 \%$, while no re-bleeding was encountered. This may be due to our policy to operate within 24 hours of patients' arrival and early referral of patients to our center.

\section{Demography}

In general, PICA aneurysms tend to present at an earlier age as compared with other aneurysms. The mean age as reported in many large series is in the fifth decade, with Lewis et $\mathrm{al}^{6}$ reporting 51 years, Lehto et $\mathrm{al}^{9}$ as 52 years, and Dernbach et a $1^{10}$ even lower at 44.7 years. In their series, Lehto et $\mathrm{al}^{9}$ compared the age of patients with distal PICA aneurysms in eighty cases with those cases who had aneurysms located at other locations during the same study period. They, however, never found a significant difference in the ages, as 
Table 4 Presentation, location, and outcome of the posterior inferior cerebellar artery aneurysms

\begin{tabular}{|c|c|c|c|c|c|}
\hline $\begin{array}{l}\text { Serial } \\
\text { number }\end{array}$ & Age/sex & Presentation & $\begin{array}{l}\text { Location of } \\
\text { aneurysm }\end{array}$ & Course at hospital & $\begin{array}{l}\text { Deficits at last } \\
\text { follow-up }\end{array}$ \\
\hline 1 & 40/female & $\begin{array}{l}\text { IV ventricle hemorrhage } \\
\text { with HCP }\end{array}$ & VA-PICA origin & $\begin{array}{l}\text { Postcoiling per- } \\
\text { sistent HCP, under- } \\
\text { went shunt }\end{array}$ & $\begin{array}{l}12 \text { months, no } \\
\text { deficits }\end{array}$ \\
\hline 2 & 60/female & III and IV ventricle blood & VA-PICA origin & Uneventful & $\begin{array}{l}12 \text { months, no } \\
\text { deficits }\end{array}$ \\
\hline 3 & 55/female & $\begin{array}{l}\text { Ambient cistern and IV } \\
\text { ventricle blood }\end{array}$ & $\begin{array}{l}\text { Lateral medullary } \\
\text { segment }\end{array}$ & Uneventful & $\begin{array}{l}3 \text { months, no } \\
\text { deficits }\end{array}$ \\
\hline 4 & 58/female & $\begin{array}{l}\text { Blood in lateral and IV } \\
\text { ventricles }\end{array}$ & $\begin{array}{l}\text { Anterior medullary } \\
\text { segment }\end{array}$ & Uneventful & $\begin{array}{l}24 \text { months, no } \\
\text { deficits }\end{array}$ \\
\hline 5 & 57/male & IV ventricle blood & $\begin{array}{l}\text { Vermian AVM with } \\
\text { cortical segment } \\
\text { aneurysm }\end{array}$ & $\begin{array}{l}\text { Developed brain } \\
\text { stem infract and } \\
\text { with HCP, under- } \\
\text { went shunting } \\
\text { procedure }\end{array}$ & Did not follow up \\
\hline
\end{tabular}

Abbreviations: AVM, arteriovenous malformation; HCP, hydrocephalus; PICA, posterior inferior cerebellar artery; VA, vertebral artery.

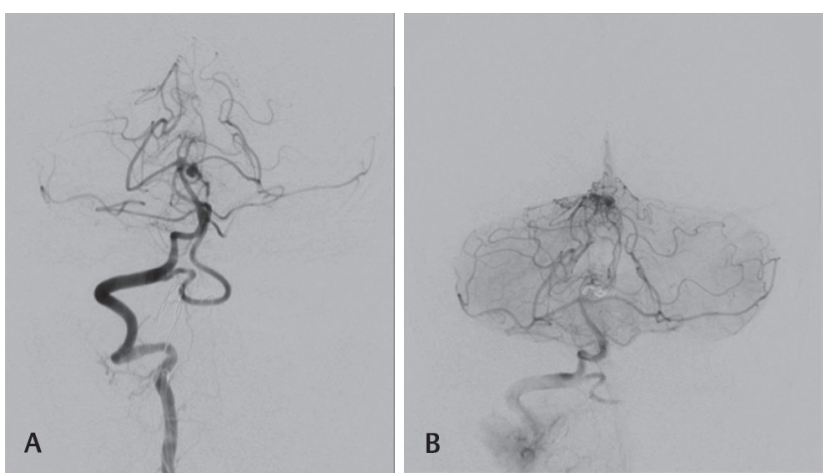

Fig. 7 (A) Diagnostic cerebral angiogram of cortical segment posterior inferior cerebellar artery aneurysm with vermian arteriovenous malformation-saccular aneurysm from the 5 th segment. (B) Diagnostic cerebral angiogram of cortical segment posterior inferior cerebellar artery aneurysm with vermian arteriovenous malformation.

the mean age of other cases presenting with aneurysms was 49 years. In our series, the mean age was 51 years, ratifying with most previous series.

\section{Aneurysmal Characteristics}

PICA has been defined in most series as the most proximal artery originating from the VA and has been divided into five segments, with three medullary segments further branching to variable numbers of perforators of different lengths and trajectories. Four-vessel angiography is the main modality of detection of aneurysm. It is also central to the detection of site, size, other vascular abnormalities, and associated aneurysms. Vascular abnormalities include PICA reduplication, anterior inferior cerebellar artery-supplying PICA territory, absence of opposite artery, and fetal-type circulation. This information is crucial for planning surgical management. Initial angiographic studies can miss the aneurysm, even when the clinical and radiological suspicion is high. Repeat angiography is needed sometimes to clearly understand the anatomy and location of the aneurysm, especially with respect to the lower CNs. One of the aneurysms in our study was missed in initial angiography, which was showed in repeat angiography due to vasospasm.

Most commonly, distal PICA aneurysms arise from lateral medullary segment followed by tonsillomedullary segment as seen in a large series of Tokimura et $\mathrm{al}^{11}$ and Lehto et $\mathrm{al}^{9}$ In our series, however, aneurysms in the tonsillo-medullary segment were the most common site, with 40\% (8/20) of all the PICA aneurysms with the anterior medullary or VA PICA junction being the origin of 35\% (7/20) aneurysms.

On the basis of morphology, PICA aneurysms have been classified as saccular or fusiform. Dissecting aneurysms have also been described, but their treatment is similar to fusiform aneurysms and hence has been considered together here. Fusiform aneurysms vary from 6 to $62 \%$ in various studies, ${ }^{6,9,11}$ and in our series, it was $10 \%(2 / 20)$.

CT scan of the head shows the site of the bleed, which gives a clue to the location of the aneurysm. Rupture of proximal PICA aneurysms is often diagnosed by the presence of hyperdensity in the ipsilateral basal cisterns that may or may not accompany an extension into the fourth ventricle. Eight (40\%) aneurysms of the proximal PICA segments demonstrated SAH with extension into the ventricular system. Patients can have only fourth ventricular hemorrhage with no evidence of any cisternal, cortical, or sulcal blood. This presentation is due to trickling of blood through the foramen of Luschka or Magendie after aneurysmal rupture. These patients almost always have distally located PICA aneurysms. Aneurysms that arise from the tonsillomedullary segment are known to rupture solely into the fourth ventricle. ${ }^{12}$ In our study, only fourth ventricle hemorrhage was seen in $25 \%$ of patients (5/20). Out of these, four cases had distal PICA aneurysm. The incidence of IVH due to PICA aneurysm rupture can range from 83 to $100 \%,{ }^{13,14}$ which also contributes to poorer outcomes due to vasospasm and later development of hydrocephalus. Our series also reports IVH rates of $80 \%(16 / 20)$. 


\section{Treatment}

Microsurgery remains the bedrock for treating PICA aneurysms, with planning depending on size, location, shape, presentation, and clinical condition of the patient. Midline approaches are safe, familiar, and more reasonable, especially for distal PICA aneurysms. Neurovascular conflicts, proximal perforators, and eloquent areas influence dissection and clipping techniques. Options include direct clipping, clipping with wrapping, wrapping, resection, proximal occlusion or trapping with revascularization, and distal occlusion. ${ }^{9}$ Dissection and clipping of these aneurysms may lead to lower $\mathrm{CN}$ handling and subsequently cause lower $\mathrm{CN}$ palsy that even if transient can be very alarming to the patient, especially if not explained prior to the surgery. The rate of lower $\mathrm{CN}$ paresis after surgical clipping of proximal PICA aneurysms can vary between 10 and $45 \%{ }^{1,7}$ In our series, there was only one such case that had presented preoperatively with lower CN symptoms, notably, improving at his 6-month follow-up visit. This is probably because of the early presentation of cases and emergent treatment within a 24-hour window period after presentation at our institute. Furthermore, usually, the related morbidity is self-limiting and will usually improve in $\sim 3$ to 6 months.

Although for anterior medullary segment, far-lateral approach provides the best exposure to the cerebellomedullary fissure, the recent trend has been on a tailored approach. Seoane et $\mathrm{al}^{15}$ reported a surgical series using the far-lateral approach to PICA aneurysms without condylar resection. Rodríguez-Hernández and Lawton described the vagoaccessory triangle that is bordered medially by the medulla, laterally by the spinal accessory nerve (CN XI), and superiorly

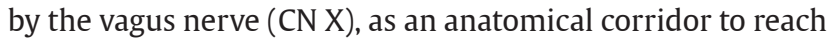
the PICA aneurysms. ${ }^{2}$ As for distal PICA aneurysms, midline approach is, without doubt, sufficient. In our series, we have used the far-lateral approach with condylar resection only in $25 \%(5 / 20)$ of the cases, with the majority (4/5) being anterior medullary or VA-PICA junction cases with acceptable complication rates. Other improvised techniques have been described such as the lateral suboccipital approach, the lateral suboccipital transcondylar approach, removal of the posterior condyle, $\mathrm{C} 1$ lateral mass, and/or the jugular tubercle, all of which help in widening the surgical corridor. ${ }^{16}$ Proximal control of VA can be secured by the far-lateral approach and dissection of the arachnoid caudal to the IX and X CNs, avoiding the resection of the posterior lip of the foramen magnum.

Complication in our series was more related to the development of hydrocephalus rather than lower $\mathrm{CN}$ paralysis, with $20 \%$ (4/20) cases requiring permanent shunting of cerebrospinal fluid (CSF). Recent studies estimate that hydrocephalus, communicating or noncommunicating, is reported in up to $67 \%$ of patients with IVH. ${ }^{17}$ The most plausible theory is that a blood clot blocks the CSF drainage pathway. The phenomenon usually takes place in the narrowest parts of the CSF pathway, namely the cerebral aqueducts or in the outlets of the fourth ventricle. These small and multiple clots can form all over the ventricular lining, causing obstruction to the pathway of CSF via the arachnoid villi leading into the venous sinuses and small blood vessels. ${ }^{18}$
There have been a few large surgical series describing either distal PICA aneurysms alone or in combination with VA aneurysms ( - Table 5 ).

\section{Endovascular versus Clipping}

Recently, the trend has been for endovascular management of PICA aneurysms, due to the concern regarding lower $\mathrm{CN}$ morbidity and avoiding critical perforators, especially at the proximal segments. Coil embolization has been the primary method, being most suitable for saccular aneurysms with narrow necks. ${ }^{31}$ PICA aneurysms have also been treated with flow diverters, although recurrences have been seen because PICA is an end vessel and thus usually without significant collaterals may keep the proximal aspect of the aneurysm patent. ${ }^{32}$ Endovascular parent vessel occlusion has also been used with success, especially in fusiform and distal aneurysm cases where sacrifice of the parent artery rarely leads to deficits. However, complication rates of $13 \%$ have been reported with embolization of PICA. ${ }^{33}$ This may be due to a multitude of reasons. Superselective catheterization of this tortuous and often variable artery is difficult and may even be impossible for distal aneurysm cases. In addition, with small aneurysms, there is a chance of "jumping" of the catheter or guidewire into the sac, leading to inadvertent rupture. This also leads to an unfavorable anatomy, making it difficult for further coils to be introduced. There may, however, be a place for coiling for the more proximal segments (anterior medullary/VA-PICA junction) as surgical clipping may be tenuous in a bid to preserve brain stem perforators. Another major finding corroborating with previous series is that surgical resection of AVM with aneurysmal clipping is superior to embolization or coiling as can be seen with one case of AVM with aneurysm in our series. ${ }^{31}$

A situation where neither coiling nor clipping is safe is blister aneurysms of PICA. Here, the outer wall of the aneurysm comprises only the adventitia and/or thrombus that separates the artery from the overlying pia. Here, clipping can cause rupture at the neck of the aneurysm and stent assisted or flow diverter placement is difficult due to the small diameter of the PICA. Parent artery occlusion is often tried but may lead to deficits. Here, a novel technique of endovascular embolization with detachable coils while preserving the parent artery using a combination of soft three-dimensional coil technology and low-profile microcatheter allows good coil positioning, while the microcatheter itself maintains the patency of the parent vessel. ${ }^{34}$

Another option for these difficult cases is intracranial-to-intracranial (IC-IC) bypass with trapping of the aneurysm. In a largest such series spanning 17 years, Abla et $\mathrm{al}^{35}$ described 129 PICA aneurysms in 125 patients treated microsurgically. A total of 35 IC-IC bypasses were performed as part of PICA aneurysm management. All aneurysms were completely occluded with $94 \%$ of bypasses patent. Ischemic complications were seen only in two patients in whom the bypasses occluded, and permanent lower CN morbidity was limited to three patients. They concluded that the PICA aneurysms allow the application of IC-IC bypass better than any other cerebral aneurysms. An algorithmic approach 
Table 5 A complete review of the major surgical series of pica aneurysms

\begin{tabular}{|c|c|c|c|c|c|}
\hline Series & Years & $\begin{array}{l}\text { Number of } \\
\text { aneurysms }\end{array}$ & Remarks & Complications (\%) & Major approach (\%) \\
\hline Lehto et $\mathrm{al}^{9}$ & 2014 & 91 & Distal PICA & $\begin{array}{l}18(22.5) \text { patients died, } 52(65) \\
\text { independent or previous state } \\
\text { of living }\end{array}$ & Midline suboccipital \\
\hline Horiuchi et al ${ }^{19}$ & 2007 & 24 & Distal PICA & $\begin{array}{l}22(81.5) \text { clipping } \\
2 \text { (7.4) wrapping } \\
1 \text { (3.7) ligate proximally } \\
1 \text { (3.7) coiling }\end{array}$ & $\begin{array}{l}\text { Lateral suboccipital } \\
\text { approach }\end{array}$ \\
\hline Al-Khayat et al ${ }^{20}$ & 2005 & 52 & $\begin{array}{l}\text { Lower cranial nerve } \\
\text { deficits in PICA }\end{array}$ & $\begin{array}{l}\text { Lower cranial nerve palsy } 25 \\
(48.1)\end{array}$ & $\begin{array}{l}\text { Lateral suboccipital } \\
\text { approach }\end{array}$ \\
\hline$D^{\prime}$ Ambrosio et $\mathrm{al}^{21}$ & 2004 & 20 & $\begin{array}{l}\text { PICA aneurysms } \\
\text { (unruptured) }\end{array}$ & $\begin{array}{l}\text { Two patients underwent tran- } \\
\text { sient vocal cord palsy } \\
3 \text { CSF leak } \\
14(70) \text { HCP }\end{array}$ & Far-lateral approach \\
\hline Nussbaum et $\mathrm{al}^{22}$ & 2003 & 7 & Fusiform distal PICA & Not specified & Far-lateral approach \\
\hline Lewis et $\mathrm{al}^{6}$ & 2002 & 20 & $\begin{array}{l}\text { Distal PICA with } 6 \\
\text { (30\%) AVM }\end{array}$ & $\begin{array}{l}\text { Shunt } 9(47) \\
\text { Ataxia } 5(26) \\
\text { Dysphagia } 2(10.5)\end{array}$ & $\begin{array}{l}\text { Far-lateral transcon- } \\
\text { dylar approach in } 19 \\
(86)\end{array}$ \\
\hline Matsushima et al ${ }^{23}$ & 2001 & 8 & PICA aneurysms & & \\
\hline Horowitz et $\mathrm{al}^{24}$ & 1998 & 38 & PICA aneurysms & $\begin{array}{l}25(60) \text { new neurological deficit } \\
18(47) \text { vocal cord palsy } \\
14(37) \text { dysphagia } \\
1(3) \text { hearing loss, facial } \\
\text { weakness }\end{array}$ & $\begin{array}{l}\text { Lateral suboccipital } \\
\text { approach (84) } \\
\text { RMSOC } 6(16)\end{array}$ \\
\hline Bertalanffy et $a^{25}$ & 1998 & 27 & PICA aneurysms & PICA aneurysms & PICA aneurysms \\
\hline Sano et $\mathrm{al}^{26}$ & 1997 & 16 & $\begin{array}{l}\text { Dissecting VA } \\
\text { aneurysms }\end{array}$ & $\begin{array}{l}4 \text { good, } 1 \text { fair, } 1 \text { died } \\
2 \text { excellent, } 1 \text { good, } 1 \text { fair }\end{array}$ & $\begin{array}{l}\text { Surgical clipping-6, } \\
\text { trapping }-5\end{array}$ \\
\hline Andoh et al ${ }^{27}$ & 1992 & 38 & $\begin{array}{l}26 \text { junction PICA VA } \\
10 \text { VA } \\
2 \text { VA-BA junction }\end{array}$ & Good result-22 (81) & Not specified \\
\hline Yamaura et $a^{28}$ & 1990 & 24 & $\begin{array}{l}\text { Dissecting PICA } \\
\text { aneurysms }\end{array}$ & $\begin{array}{l}\text { Lower cranial nerve-5 (26) } \\
\text { Lateral medullary-3 (16) }\end{array}$ & $\begin{array}{l}19(79) \text { surgery } \\
10(52) \text { clipping } \\
7 \text { (36) wrapping }\end{array}$ \\
\hline Yamaura $^{29}$ & 1988 & 86 & VA aneurysm & $\begin{array}{l}\text { Lower cranial nerve-11(16) } \\
\text { Lateral medullary syndrome-3 } \\
\text { (4) } \\
\text { Severe deficit-3 (4) }\end{array}$ & $\begin{array}{l}68(79) \text { surgi- } \\
\text { cal intervention } \\
\text { lateral suboccipital } \\
\text { approach }\end{array}$ \\
\hline Gács et $a^{30}$ & 1983 & 16 & $\begin{array}{l}\text { PICA aneurysms } \\
\text { Six patients associ- } \\
\text { ated with AVM }\end{array}$ & $\begin{array}{l}\text { Good-11 (69) } \\
\text { Residual deficit-4 (25) } \\
\text { Poor outcome-1 (6) } \\
\text { Died-1 (6) }\end{array}$ & Not specified \\
\hline
\end{tabular}

Abbreviations: AVM, arteriovenous malformation; BA, basilar artery; CSF, cerebrospinal fluid; HCP, hydrocephalus; PICA, posterior inferior cerebellar artery; $\mathrm{VA}$, vertebral artery.

is advocated: trapped aneurysms of the PICA origin (p1 segment) are to be revascularized with a PICA-PICA bypass, with PICA reimplantation being the alternative; trapped p2 segment aneurysms can be reanastomosed, bypassed in situ, or reimplanted; distal p3 segment aneurysms can be reanastomosed or revascularized with a PICA-PICA bypass; and lastly the aneurysms of the $\mathrm{p} 4$ segment that are too distal for any of the PICA-PICA bypass can be reanastomosed. Interpositional grafts are to be reserved for when these three primary options are not possible. Such an option is often feasible and provides exceptional results.
Surgical clipping provides what coiling leaves to be desired. Undervision dissection of the aneurysm and avoidance of neurovascular structures are the best method to avoid complications. ${ }^{36}$ Bohnstedt et $\mathrm{al}^{37}$ published the largest series so far, valuing both microsurgical and endovascular treatments of 102 PICA aneurysms and have favored microsurgical clipping over coiling. Sejkorová et a ${ }^{38}$ also reported their series of 81 cases of PICA aneurysms during a 15-year period and found more recurrences in the coiled group. A meta-analysis by Petr et $\mathrm{al}^{39}$ of 796 PICA aneurysmal cases comparing clipping and coiling has shown 
a significantly greater rate of recurrence with coiling (8.1 vs. $1.1 \%$ ) with no overall long-term differences in clinical outcome between the two treatment strategies. With the experience and review of previous surgical series and our own cases we can safely conclude that if treated early and with sufficient precision morbidity in PICA aneurysms is more likely due to complications related to SAH rather than technical hurdles in clipping the aneurysm.

\section{Limitations}

This series suffers from some significant limitations due to it inherently being a retrospective review. The absence of lower $\mathrm{CN}$ deficits is very hard to explain, but due to the small numbers and a retrospective review nature, transient lower $\mathrm{CN}$ palsies may have been missed. In addition, a far-lateral approach was used in six aneurysms despite 11 out of the 21 aneurysms being located in either the anterior medullary or lateral medullary segments. However, this might be indicative of the current need of less invasive approaches. ${ }^{2,15,16}$ However, an honest representation of available findings has been attempted along with a thorough review of available literature.

\section{Conclusion}

This series, albeit small, provides a bird's eye view into the microsurgical management of PICA aneurysms with faster referral patterns and early treatment. Lateral medullary segments and VA-PICA junction constitute the most common sites of aneurysms, with midline and lateral approaches being ideal for them, respectively. Dissection if done meticulously prevents lower $\mathrm{CN}$ morbidity, which is often transient, if present. Complications are rather due to sequelae of hemorrhage causing hydrocephalus and need for shunting, and thus close follow-up is necessary. Finally, an expert ensemble team of cerebrovascular surgeons and techniques is indispensable to treat these tricky aneurysms.

\section{Funding \\ None.}

\section{Conflict of Interest}

None declared.

\section{References}

1 Bacigaluppi S, Bergui M, Crobeddu E, Garbossa D, Ducati A, Fontanella M. Aneurysms of the medullary segments of the posterior-inferior cerebellar artery: considerations on treatment strategy and clinical outcome. Neurol Sci 2013;34(4):529-536

2 Rodríguez-Hernández A, Lawton MT. Anatomical triangles defining surgical routes to posterior inferior cerebellar artery aneurysms. J Neurosurg 2011;114(4):1088-1094

3 Lister JR, Rhoton AL, Jr. Matsushima T, Peace DA. Microsurgical anatomy of the posterior inferior cerebellar artery. Neurosurgery 1982;10(2):170-199

4 Dandy WE. Intracranial Aneurysms. Ithaca, New York: Comstock Publishing Co., Inc; 1947

5 Rizzoli HV, Hayes GJ. Congenital berry aneurysm of the posterior fossa; case report with successful operative excision. J Neurosurg 1953;10(5):550-551
6 Lewis SB, Chang DJ, Peace DA, Lafrentz PJ, Day AL. Distal posterior inferior cerebellar artery aneurysms: clinical features and management. J Neurosurg 2002;97(4):756-766

7 Peerless SJ, Drake CG. Management of aneurysms of the posterior circulation. In: Youmans JR, ed. Neurological Surgery. 4th edition., Vol. 3. Philadelphia: W.B. Saunders Co; 1990 806-1764

8 Song HH, Won YD, Kim YJ, Kim BS. The endovascular management of saccular posterior inferior cerebellar artery aneurysms. Korean J Radiol 2008;9(5):396-400

9 Lehto H, Harati A, Niemelä M, et al. Distal posterior inferior cerebellar artery aneurysms: clinical features and outcome of 80 patients. World Neurosurg 2014;82(5):702-713

10 Dernbach PD, Sila CA, Little JR. Giant and multiple aneurysms of the distal posterior inferior cerebellar artery. Neurosurgery 1988;22(2):309-312

11 Tokimura H, Yamahata H, Kamezawa T, et al. Clinical presentation and treatment of distal posterior inferior cerebellar artery aneurysms. Neurosurg Rev 2011;34(1):57-67

12 Hudgins RJ, Day AL, Quisling RG, Rhoton AL Jr, Sypert GW, Garcia-Bengochea F. Aneurysms of the posterior inferior cerebellar artery. A clinical and anatomical analysis. J Neurosurg 1983;58(3):381-387

13 Kallmes DF, Lanzino G, Dix JE, et al. Patterns of hemorrhage with ruptured posterior inferior cerebellar artery aneurysms: CT findings in 44 cases. AJR Am J Roentgenol 1997;169(4):1169-1171

14 Sadato N, Numaguchi Y, Rigamonti D, Salcman M, Gellad FE, Kishikawa T. Bleeding patterns in ruptured posterior fossa aneurysms: a CT study. J Comput Assist Tomogr 1991;15(4):612-617

15 Seoane P, Kalb S, Clark JC, et al. Far-lateral approach without drilling the occipital condyle for vertebral artery-posterior inferior cerebellar artery aneurysms. Neurosurgery 2017;81 (2):268-274

16 Viswanathan GC, Menon G, Nair S, Abraham M. Posterior inferior cerebellar artery aneurysms: operative strategies based on a surgical series of 27 patients. Turk Neurosurg 2014;24(1):30-37

17 Bu Y, Chen M, Gao T, Wang X, Li X, Gao F. Mechanisms of hydrocephalus after intraventricular haemorrhage in adults. Stroke Vasc Neurol 2016;1(1):23-27

18 Whitelaw A. Intraventricular haemorrhage and posthaemorrhagic hydrocephalus: pathogenesis, prevention and future interventions. Semin Neonatol 2001;6(2):135-146

19 Horiuchi T, Tanaka Y, Hongo K, Nitta J, Kusano Y, Kobayashi S. Characteristics of distal posteroinferior cerebellar artery aneurysms. Neurosurgery 2003;53(3):589-595, discussion 595-596

20 Al-khayat H, Al-Khayat H, Beshay J. Manner D, White J. Vertebral artery-posteroinferior cerebellar artery aneurysms: clinical and lower cranial nerve outcomes in 52 patients. Neurosurgery 2005;56(1):2-10

21 D'Ambrosio AL, Kreiter KT, Bush CA, et al. Far lateral suboccipital approach for the treatment of proximal posteroinferior cerebellar artery aneurysms: surgical results and long-term outcome. Neurosurgery 2004;55(1):39-50, discussion50-54

22 Nussbaum ES, Mendez A, Camarata P, Sebring L. Surgical management of fusiform aneurysms of the peripheral posteroinferior cerebellar artery. Neurosurgery 2003;53(4):831-834

23 Matsushima T, Matsukado K, Natori Y, Inamura T, Hitotsumatsu T, Fukui M. Surgery on a saccular vertebral artery-posterior inferior cerebellar artery aneurysm via the transcondylar fossa (supracondylar transjugular tubercle) approach or the transcondylar approach: surgical results and indications for using two different lateral skull base approaches. J Neurosurg 2001;95(2):268-274 
24 Horowitz M, Kopitnik T, Landreneau F, et al. Posteroinferior cerebellar artery aneurysms: surgical results for 38 patients. Neurosurgery 1998;43(5):1026-1032

25 Bertalanffy H, Sure U, Petermeyer M, Becker R, Gilsbach JM. Management of aneurysms of the vertebral artery-posterior inferior cerebellar artery complex. Neurol Med Chir (Tokyo) 1998;38(Suppl. 8):93-103

26 Sano H, Kato Y, Okuma I, et al. Classification and treatment of vertebral dissecting aneurysm. Surg Neurol 1997;48(6):598-605

27 Andoh T, Shirakami S, Nakashima T, et al. Clinical analysis of a series of vertebral aneurysm cases. Neurosurgery 1992;31(6):987-993, discussion 993

28 Yamaura A, Watanabe Y, Saeki N. Dissecting aneurysms of the intracranial vertebral artery. J Neurosurg 1990;72 (2):183-188

29 Yamaura A. Diagnosis and treatment of vertebral aneurysms. J Neurosurg 1988;69(3):345-349

30 Gács G, Viñuela F, Fox AJ, Drake CG. Peripheral aneurysms of the cerebellar arteries. Review of 16 cases. J Neurosurg 1983;58(1):63-68

31 Mascitelli JR, Yaeger K, Wei D, et al. Multimodality treatment of posterior inferior cerebellar artery aneurysms. World Neurosurg 2017;106:493-503

32 Kan P, Srinivasan VM, Mbabuike N, et al. Aneurysms with persistent patency after treatment with the pipeline embolization device. J Neurosurg 2017;126(6):1894-1898
33 Mukonoweshuro W, Laitt RD, Hughes DG. Endovascular treatment of PICA aneurysms. Neuroradiology 2003;45(3):188-192

34 Aronov M, Mokin M, Zelenkov A, Popugaev K, Tsarikaev A, Reutov A. Endovascular coiling of ruptured very small dissecting fusiform aneurysm of posterior inferior cerebellar artery with parent artery preservation by microcatheter auto-assistance. World Neurosurg 2019;121:152-155

35 Abla AA, McDougall CM, Breshears JD, Lawton MT. Intracranial-to-intracranial bypass for posterior inferior cerebellar artery aneurysms: options, technical challenges, and results in 35 patients. J Neurosurg 2016;124(5):1275-1286

36 Deora H, Rao KVLN, Somanna S, Srinivas D, Shukla DP, Bhat DI. Surgically managed pediatric intracranial aneurysms: how different are they from adult intracranial aneurysms? Pediatr Neurosurg 2017;52(5):313-317

37 Bohnstedt BN, Ziemba-Davis M, Edwards G, et al. Treatment and outcomes among 102 posterior inferior cerebellar artery aneurysms: a comparison of endovascular and microsurgical clip ligation. World Neurosurg 2015;83(5):784-793

38 Sejkorová A, Petr O, Mulino M, et al. Management of posterior inferior cerebellar artery aneurysms: what factors play the most important role in outcome? Acta Neurochir (Wien) 2017;159(3):549-558

39 Petr O, Sejkorová A, Bradáč O, Brinjikji W, Lanzino G. Safety and efficacy of treatment strategies for posterior inferior cerebellar artery aneurysms: a systematic review and meta-analysis. Acta Neurochir (Wien) 2016;158(12):2415-2428 